\title{
Effect of the calcium antagonist nifedipine on intraocular pressure in normal subjects
}

\author{
S P KELLY' AND T J WALLEY²
}

From the 'Department of Ophthalmology, Leicester Royal Infirmary, Leicester LE1 5WW, and the ${ }^{2}$ Department of Pharmacology and Therapeutics, University of Leicester, Leicester LE2 $7 L X$

SUMMARY We studied the effects of nifedipine, a calcium antagonist, given intravenously and orally, on intraocular pressure in six normal volunteers. Nifedipine had no effect on intraocular pressure. Nifedipine is not contraindicated for the treatment of cardiovascular disease in glaucomatous patients and may have theoretical advantages in this situation, which are discussed.

The calcium antagonists are a group of drugs of diverse chemical structure which have the property of inhibiting the entry of ionic calcium intracellularly. This causes relaxation of smooth muscle cells and reduces tone in blood vessels. These drugs are widely used in the treatment of angina pectoris and systemic hypertension. Their effect on intraocular pressure (IOP) has been studied with conflicting results. ${ }^{1-3} \mathrm{We}$ therefore measured the IOP in normal subjects during a study of the pharmacodynamics of nifedipine, a calcium antagonist.

\section{Subjects and methods}

Six volunteers (aged 22-31, one female), on no medication, gave informed consent to participate in the study, which was approved by the local ethical committee. Disease was excluded by history and physical and ophthalmological examination, by slitlamp, and funduscopy. The subjects were studied on two days at least a week apart-a study day during which they received the trial medication and a control day during which they received no drugs. On each day the IOP was measured once in both eyes at 0900 , 1200 , and 1700 and recorded as a single figure averaged over both eyes. One observer (SPK) measured IOP while the subject sat at a Zeiss slitlamp; the observer used the same. standardised Goldmann applanation tonometer. On the study day the subjects received nifedipine intravenously, 0.75 $\mathrm{mg}$ as a bolus and $1.2 \mathrm{mg}$ hourly for six hours. After four hours they received a $20 \mathrm{mg}$ tablet of slow Correspondence to Mr S P Kelly, Manchester Royal Eye Hospital, Oxford Road, Manchester M13 9WH. release nifedipine. The IOP was recorded again at 1200 and 1700 . Mean blood pressure (=diastolic $\mathrm{BP}+1 / 3 \times$ pulse pressure) and forearm blood flow (measured by strain gauge plethysmography and expressed as percentage change from baseline) were recorded, and serial blood samples were taken for plasma nifedipine concentrations at the same times. Results were compared by repeated measures analysis of variance and are expressed as mean \pm standard error of the mean (SEM).

\section{Results}

The results are shown in Table 1. Nifedipine had no effect on IOP or mean blood pressure. There was a significant increase in forearm blood flow after nifedipine. Plasma nifedipine concentrations were $20 \pm 2 \cdot 5 \mathrm{ng} / \mathrm{ml}$ and $27 \pm 4 \cdot 1 \mathrm{ng} / \mathrm{ml}$ at 1200 and 1700 respectively. The only side effect was headache in four subjects on each day.

Table 1 Intraocular pressure (IOP, $\mathrm{mmHg}$ ), mean blood pressure ( $\mathrm{MBP}, \mathrm{mmHg})$, and forearm blood flow $(\mathrm{FBF}, \%$ change) during nifedipine treatment and IOP alone on a control day (mean $\pm S E M$ )

\begin{tabular}{|c|c|c|c|c|c|c|c|c|c|}
\hline \multirow[t]{2}{*}{ Time: } & \multicolumn{3}{|l|}{0900} & \multicolumn{3}{|l|}{1200} & \multicolumn{3}{|l|}{1700} \\
\hline & $I O P$ & $M B P$ & $F B F$ & $I O P$ & $M B P$ & $F B F$ & $I O P$ & $M B P$ & $F B F$ \\
\hline Control & $\begin{array}{l}12 \cdot 6 \\
\pm 1 \cdot 8\end{array}$ & - & - & $\begin{array}{l}12 \cdot 6 \\
\pm 1 \cdot 2\end{array}$ & - & - & $\begin{array}{l}13.0 \\
\pm 2.6\end{array}$ & - & - \\
\hline Nifedipine & $\begin{array}{l}13 \cdot 6 \\
\pm 2 \cdot 3\end{array}$ & $\begin{array}{l}90 \cdot 5 \\
\pm 9 \cdot 6\end{array}$ & 0 & $\begin{array}{l}11 \cdot 6 \\
\pm 1.7\end{array}$ & $\begin{array}{l}87 \cdot 2 \\
\pm 10 \cdot 9\end{array}$ & $\begin{array}{l}45^{*} \\
\pm 22\end{array}$ & $\begin{array}{l}10 \cdot 0 \\
\pm 2 \cdot 2\end{array}$ & $\begin{array}{l}88 \cdot 2 \\
\pm 11 \cdot 0\end{array}$ & $\begin{array}{l}37^{*} \\
\pm 15\end{array}$ \\
\hline
\end{tabular}

${ }^{*} p<0 \cdot 05$. Otherwise no significant effect of nifedipine. 


\section{Discussion}

We have shown that systemic nifedipine has no effect on IOP in normal subjects. The pharmacology of aqueous humour dynamics is complicated. Alpha and beta adrenergic, serotoninergic, muscarinic, and benzodiazepine receptors have all been found in the anterior uveal tract. ${ }^{+}$Species differences have added to the difficulty of studying receptor pharmacology in the eye. For example, topical haloperidol has been shown to cause a significant reduction in IOP in experimental animals but not in normal humans. ${ }^{5}$

There have been three previous studies of effects of calcium antagonists on IOP. Schnell ${ }^{1}$ found that a single $20 \mathrm{mg}$ dose of nifedipine sublingually caused an acute fall in IOP in glaucomatous patients, while repeated oral doses had no effect in these patients or normal subjects. Monica et al. ${ }^{2}$ found that a single 20 $\mathrm{mg}$ oral dose of nitrendipine, a similar newer calcium antagonist, reduced both IOP and systemic vascular resistance in patients with essential hypertension and normal IOP. Beatty et al. ${ }^{3}$ studied three calcium antagonists in rabbits and normal humans and found that an intravenous bolus of verapamil or diltiazem increased the IOP acutely in rabbits. Topical verapamil, diltiazem, or nifedipine also increased IOP in humans and rabbits, but oral verapamil had no effect. Beatty et al. considered that the increase in IOP could be due to ocular vasodilatation because whole eye and ciliary body blood flow were increased in the rabbits on topical verapamil, and also because pretreatment with vasoconstrictors such as $10 \%$ phenylephrine or $1 \%$ adrenaline prevented the rise in IOP.

According to the vasogenic theory of glaucoma, impaired perfusion of the optic nerve head is responsible for optic disc cupping and visual field loss. The theory has recently been reviewed by Hayreh, ${ }^{6}$ who presented evidence from fluorescein angiographic, histopathological, and experimental studies to propose that the visual field defect in glaucoma and anterior ischaemic optic neuropathy, which may be indistinguishable, are due to reduced perfusion in the prelaminar portion of the optic disc. The inaccessibility of the optic nerve head makes measurement of optic nerve perfusion even more difficult than measurement of cerebral perfusion. ${ }^{7}$ Therefore in the absence of direct evidence we must extrapolate from studies in experimental animals. Choroidal blood flow has been shown to reflect cerebral blood flow in primates. ${ }^{8}$ Lydtin et al. have shown that nifedipine causes marked peripheral and minor cerebral vasodilatation, ${ }^{9}$ so nifedipine could theoretically increase choroidal perfusion. An improvement in choroidal and optic nerve head perfusion by nifedipine might therefore reduce or prevent visual field loss in glaucoma, provided that nifedipine itself did not increase the IOP. Our work shows that nifedipine induced peripheral and presumably cerebral and ocular vasodilatation (though we could not measure this) but does not increase IOP.

Plasma concentrations of nifedipine achieved in this study are similar to those in the treatment of hypertension " and were adequate to cause vasodilatation. Traditionally it is stated that acute reduction in systemic blood pressure in patients with glaucoma may cause progression of visual field loss, possibly due to reduced ocular perfusion." An extreme view was that "glaucoma patients with moderate (systemic) hypertension should not be treated with hypotensive drugs'. ${ }^{2}$ This theory is still controversial today. ${ }^{13}$

We believe that, since nifedipine does not increase the IOP at a plasma level commonly seen in the treatment of hypertension and sufficient to cause vasodilatation, and since it and similar drugs improve cerebral perfusion in humans and ocular perfusion in rabbits, the calcium antagonists are suitable systemic drugs when glaucoma and hypertension coexist.

We thank Mr A R Fielder, Professor A R Rosenthal, and Professor D B Barnett for their advice, and Bayer UK for supplying nifedipine and drug assay. TW was supported by a grant from Bayer UK.

\section{References}

1 Schnell D. Response of intraocular pressure in normal subjects and glaucoma patients to single and repeated doses of the coronary drug Adalat. In: Lochner W, Engel H-J, Lichtlen PR, eds. Second International Adalat Symposium. Berlin: Springer, 1975: 290-302.

2 Monica ML, Hesse RJ, Messerli FH. The effect of a calcium channel blocking agent on intraocular pressure. $A m J$ Ophthalmol 1983; 96: 814 .

3 Beatty JF, Krupin T, Nichols PF, Becker B. Elevation of intraocular pressure by calcium channel blockers. Arch Ophthalmol 1984; 102: 1072-6.

4 Sugrue MF. Preclinical evaluation of anti-glaucoma drugs. Res Clin Forums 1985; 7: 75-80.

5 Lavin MS, Andrews V. Is topical haloperidol a useful glaucoma treatment? BrJ Ophthalmol 1986; 70: 448-50.

6 Hayreh SS. Inter-individual variation in the blood supply of the optic nerve head. Its importance in various ischaemic disorders of the optic nerve head and glaucoma, low tension glaucoma and allied disorders. Doc Ophthalmol 1985; 59: 217-46.

7 Bill A. Physiological aspects of the circulation of the optic nerve. In: Heilmann K, Richardson KT, eds. Glaucoma: conceptions of a disease. Stuttgart: Thieme, 1978: 97-103.

8 Wilson TM, MacKenzie ET, Strang R. Factors influencing ocular blood flow. In: Cant JS, ed. Vision and circulation. London: Kimpton, 1976: 45-9.

9 Lydtin H, Lohmuller G, Lohmuller R, Schmitz H, Walter I. Comparative studies with Adalat and other antianginal drugs. In: Jatene AD, Lichtlen PR, eds. Third International Adalat Symposium. Amsterdam: Excerpta Medica, 1976: 98-106.

10 Banzet O, Colin JN, Thibonnier M, Singlas E, Alexandre JM, 
Corval P. Acute antihypertensive effect and pharmacokinetics of a tabiet preparation of nifedipine. Eur J Clin Pharmacol 1983; 24: $145-50$.

11 Harrington DO. The pathogenesis of the glaucoma field. Clinical evidence that circulatory insufficiency in the optic nerve is the primary cause of visual loss in glaucoma. Am J Ophthalmol 1959; 47: $177-85$
12 François J, Neetens A. The detcrioration of the visual ficld in glaucoma and the blood pressure. Doc Ophthalmol 1970; 28: 70-132.

13 Epstein DC. In: Epstein DC, ed. Chandler and Grant's Glaucoma. 3rd ed. Philadelphia: Lea and Febiger, 1986: 97-8.

Accepted for publication 20 January 1986. 